\title{
Comparative Effectiveness of Laterally Placed Expandable versus Static Interbody Spacers: A 1-Year Follow-Up Radiographic and Clinical Outcomes Study
}

\author{
Yan Michael $\mathrm{Li}^{1}$, Richard Francis Frisch ${ }^{2}$, Zheng Huang ${ }^{3}$, James Edward Towner ${ }^{1}$, \\ Yan Icy Li ${ }^{1}$, Amber Lynn Edsall ${ }^{4}$, Charles Ledonio ${ }^{4}$ \\ ${ }^{I}$ Department of Neurosurgery and Oncology, Medical Center, School of Medicine and Dentistry, University of Rochester, Rochester, NY, USA \\ ${ }^{2}$ Southeastern Spine Institute, Mt. Pleasant, SC, USA \\ ${ }^{3}$ Department of Orthopaedics, Guanghua Hospital, Shanghai, China \\ ${ }^{4}$ Musculoskeletal Education and Research Center (MERC), A Division of Globus Medical, Inc., Audubon, PA, USA
}

\begin{abstract}
Study Design: Retrospective chart review.
Purpose: This study compared the clinical and radiographic outcomes of patients treated with expandable and static interbody spacers following minimally invasive lateral lumbar interbody fusion (MIS-LLIF) with 12-month follow-up.

Overview of Literature: A common surgical option for the treatment of degenerative disk disease (DDD) is MIS-LLIF using static or expandable spacers to restore disk height (DH), neuroforaminal height $(\mathrm{NH})$, and segmental lordosis. Static spacers may require excessive trialing and aggressive impaction, potentially leading to endplate disruption and subsidence. Expandable spacers allow for in situ expansion to help address complications associated with static spacers.

Methods: This is an Institutional Review Board-exempt review of 69 patients (static, $n=32$; expandable, $n=37$ ) diagnosed with DDD who underwent MIS-LLIF at 1-2 contiguous level(s) using static or expandable spacers. Radiographic and clinical outcomes were collected and compared at pre- and postoperative time points up to 12 months.

Results: The expandable group had a significantly higher mean change in Visual Analog Scale (VAS) scores at 6 weeks, 6 months,

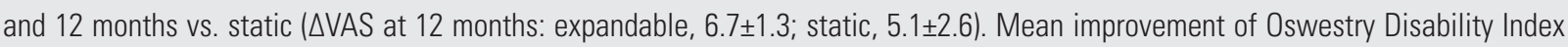
(ODI) scores at 3, 6, and 12 months were significantly better for the expandable group vs. static ( $\triangle \mathrm{ODI}$ at 12 months: expandable, 63.2 \pm 13.2 ; static, 29.8 23.4). Mean DH and NH significantly increased at final follow-up for both groups, with no significant difference in $\mathrm{DH}$ improvement between groups. The expandable mean NH improvement at 6 weeks and 6 months was significantly greater vs. static. Segmental lordosis significantly improved in the expandable group at all time intervals vs static. Subsidence rate at 12 months was significantly lower in the expandable group $(1 / 46,2.2 \%)$ vs. static $(12 / 37,32.4 \%)$.

Conclusions: Expandable spacers resulted in a significantly lower subsidence rate, improve segmental lordosis, and VAS and ODI outcomes at 12 months vs. static.
\end{abstract}

Keywords: Minimally invasive surgical procedures; Spinal fusions; Lmplants and prostheses

Received Aug 9, 2019; Revised Nov 14, 2019; Accepted Dec 26, 2019

Corresponding author: Amber Edsall

Musculoskeletal Education and Research Center (MERC), A Division of Globus Medical, Inc., 2560 General Armistead Avenue, Audubon, PA 19403, USA

Tel: +1-610-930-1800 (x2475), Fax: +1-610-930-2042, E-mail: AEdsall@globusmedical.com 


\section{Introduction}

Lateral lumbar interbody fusion (LLIF) is a popular retroperitoneal transpsoas approach for lumbar spine interbody fusion [1]. This approach minimizes the risk of complications associated with other approaches such as anterior lumbar interbody fusion, posterior lumbar interbody fusion, and transformational lumbar interbody fusion [2,3].

Bagby [4] pioneered the use of static interbody spacers for spinal arthrodesis, which has become the gold standard device for lumbar interbody fusion procedures $[5,6]$. To achieve sagittal correction, the interbody spacer is a critical component to the success of the lateral procedure and the preservation or restoration of sagittal alignment is a significant predictor in determining patient outcomes [7-12]. Components of sagittal alignment correction include: maximizing disk height (DH), increasing segmental lordosis, and achieving adequate indirect decompression; all are crucial for optimal outcomes [7].

The effects of increasing lordosis without proportional increases of $\mathrm{DH}$ has conflicting results in the literature [13]. It was noted by Folman et al. [14] that large lordotic interbody spacer designs present a challenge to insert in a collapsed disk space and their subsequent use compromises stability in extension and axial rotation [15]. Favorable clinical outcomes do exist with the use of static interbody spacers; however, there are also less desirable outcomes associated with static spacers, such as iatrogenic endplate damage due to excessive trialing and forceful impaction, which leads to implant subsidence and other complications [16-20]. Kim et al. [21] demonstrated in their retrospective study of 50 patients that the use of an uninterrupted, continuously expandable interbody device showed promising clinical outcomes and restoration of intervertebral $\mathrm{DH}$. The expandable spacer has the advantage of being inserted in a collapsed state and continuously expanding the device in situ [22-24]. Advancements in expandable technology allow for the interbody cages to expand in height and lordosis in a controlled fashion. However, there has been a lack of studies that compare the clinical outcomes associated with expandable interbody spacers and these studies are needed to generate evidence on effectiveness and safety of this technology. The objective of this study is to compare the clinical and radiographic outcomes of patients who underwent minimally invasive lateral lumbar interbody fusion (MIS-LLIF) using

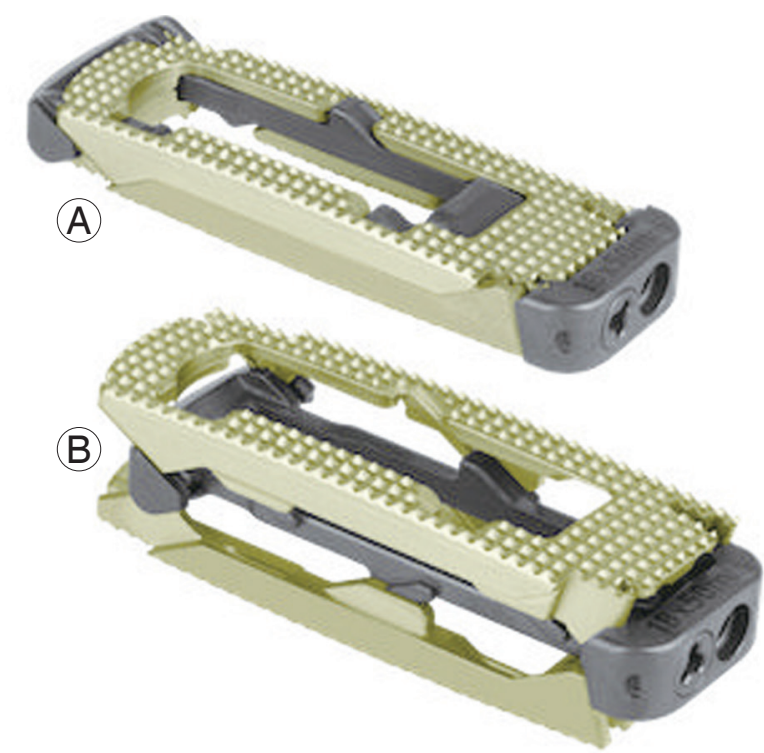

Fig. 1. Oblique view of continuously expandable interbody spacer in minimized (A) and expanded (B) forms (RISE L Globus Medical Inc., Audubon, PA, USA).

expandable and static interbody spacers (Fig. 1).

\section{Materials and Methods}

\section{Patient population}

This is an Institutional Board Review-exempt, multi-site, multi-surgeon, retrospective clinical study. It included 69 patients and 87 operative levels with a diagnosis of degenerative disk disease at one or two contiguous levels from L1 to L5 with grade 1 spondylolisthesis. All patients underwent a MIS-LLIF surgery using either an expandable interbody spacer (RISE-L; Globus Medical Inc., Audubon, PA, USA) or a static interbody spacer (TransContinental; Globus Medical Inc.), with posterior stabilization (Fig. 1). Data was collected preoperatively and postoperatively at 6 weeks, 3, 6, and 12 months. Patient self-assessment forms and radiographic records were used to assess the clinical and radiologic outcomes.

\section{Surgical technique}

While under general anesthesia, patients were placed in the lateral decubitus position and secured to the operating table with adhesive tape. Under fluoroscopic guidance, an oblique incision was made at the symptomatic disk segment. Blunt dissection was performed under direct visualization through the subcutaneous tissue, external and 


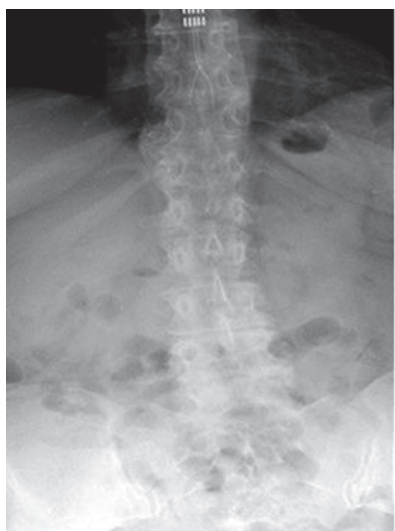

(A)
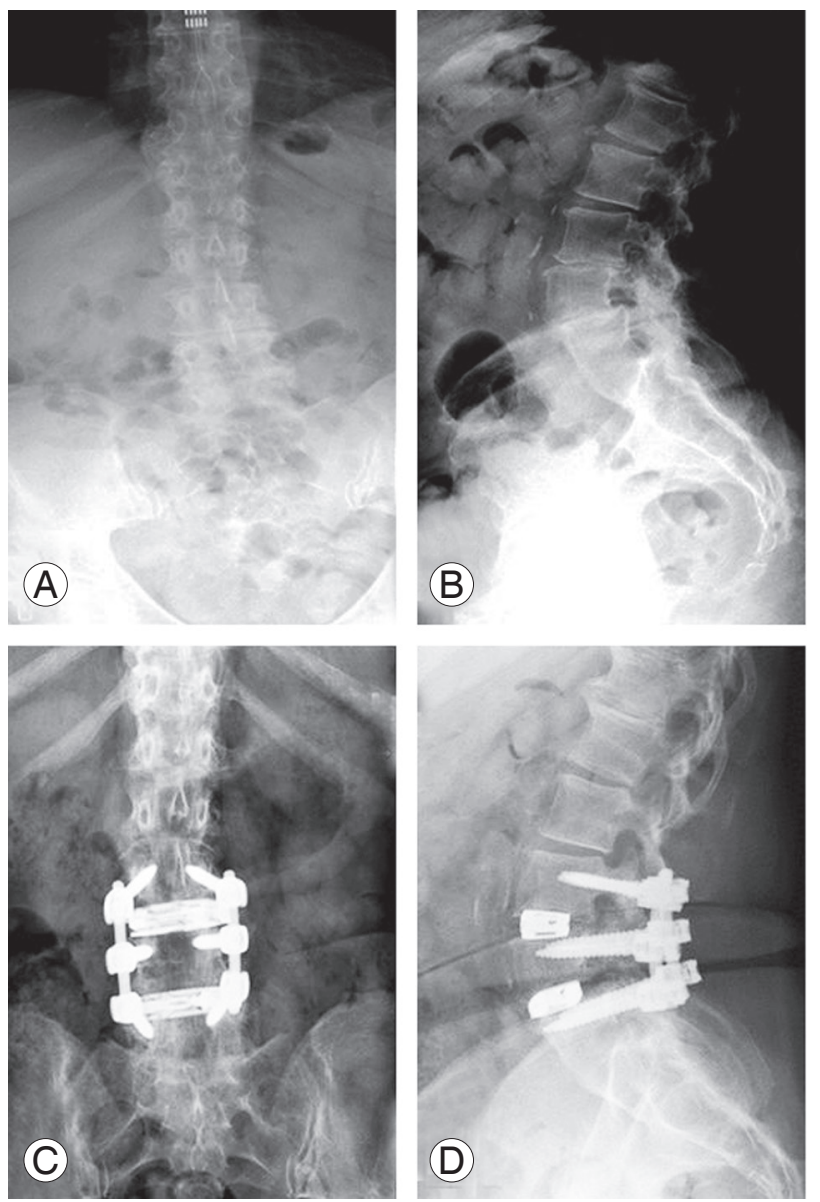

Fig. 2. Preoperative $A P(A)$ and lateral $(B)$ radiographs. Postoperative AP (C) and lateral (D) radiographs of a two-level minimally invasive lateral lumbar interbody fusion at $L 3 / 4$ and $L 4 / 5$. Previous $L 5-S 1$ fusion occurred for this patient. AP, anteroposterior.

internal oblique muscles, and transversus abdominis. The retroperitoneal fat was mobilized anteriorly, exposing the underlying psoas muscle. The psoas muscle was palpated and X-rays confirmed the level and location of spinal marker. Blunt dissection was performed anteriorly to or at the very anterior part of the psoas muscle down to the operative intervertebral disk level. Neuromonitoring stimulation did not show any nerve conduction abnormalities in the lumbar plexus. After confirmation of the appropriate level via fluoroscopy, a minimally invasive retractor was docked, sequentially dilated at the segment, and then secured to the table-mounted arm. An annulotomy was then performed, followed by a discectomy and decortication of the endplates. Sequential trials were used to allow for gradual distraction of the disk space. An appropriate sized lateral cage was then selected, packed with autograft and placed at the middle or slightly anterior to the middle

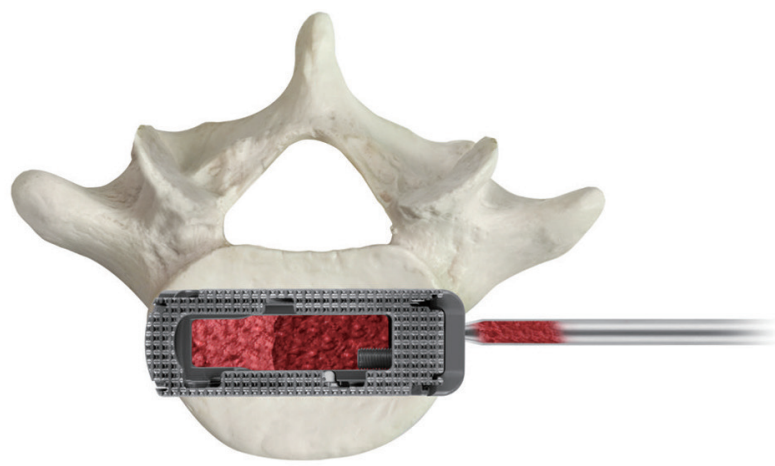

Fig. 3. Back-filling capability: additional bone graft may be packed into the graft chamber of the implant after expansion and around implant if desired.

of the interbody space (Fig. 2). The expandable spacers were then expanded to the desired height (up to $7 \mathrm{~mm}$ ) in situ and back-filled with bone graft (Fig. 3). After verification of the spacer positioning, the retractor was removed.

The expandable interbody spacer used in this study was manufactured from titanium alloy. The device is inserted at a contracted height and expanded in situ once correctly positioned within the intervertebral space, offering continuous expansion for optimal endplate-to-endplate contact. Fluoroscopy and the tactile feel of the implant in the disk space the determined appropriate expansion height. The overall height was determined through the 3 $\mathrm{Nm}$ torque safety feature using the Lateral Torque-Limiting Driver (Globus Medical Inc., Audubon, PA, USA) by counting the number of revolutions of the driver (one revolution is $0.5 \mathrm{~mm}$ of expansion). The static interbody spacer was manufactured from radiolucent polymer with titanium alloy or tantalum markers, and includes a selfdistracting leading edge for implant insertion.

\section{Outcome measures}

Patient population demographicss and perioperative data were recorded. Patient self-assessment questionnaires, such as the Visual Analog Scale (VAS) for back and leg pain and Oswestry Disability Index (ODI) were evaluated preoperatively and at 6 weeks and postoperatively at, 3, 6, and 12 months. Radiographic parameters, including $\mathrm{DH}$, neuroforaminal height $(\mathrm{NH})$, segmental lordosis, and implant subsidence were assessed (Fig. 4).

Subsidence was defined as a measured reduction in final follow-up DH greater than $2 \mathrm{~mm}$ compared to $\mathrm{DH}$ at 6 weeks postoperatively [25]. DHs were measured from the middle portion of the endplates immediately above and 


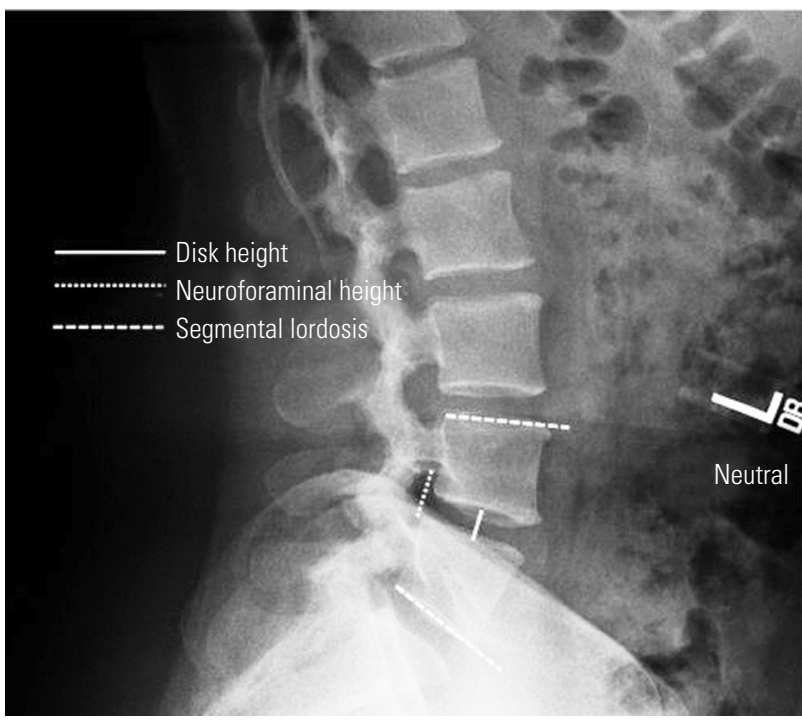

Fig. 4. Standing lateral lumbar spine radiograph with superimposed lines demonstrating the measurements assessed in this study: disk height, neuroforaminal height, and segmental lordosis.

below the referenced index levels on the lateral plane. $\mathrm{NH}$ was measured as the distance from the inferior pedicle wall of the level above to the superior pedicle wall of the level below. Segmental lordosis was measured from inferior endplate of the caudal vertebral body to the superior endplate of the cephalad vertebral body.

\section{Statistical analysis}

Statistical analysis was performed using IBM SPSS ver. 20.0.0 software for Windows (IBM Corp., Armonk, New York, USA). Descriptive statistics were recorded as mean and standard deviation, or frequency and percentage, where applicable. The Wilcoxon Mann-Whitney $U$, paired and independent sampled $t$-tests, were used to calculate changes in ordinal and interval variables from preoperative to each postoperative follow-up time point. Statistical significance was set at $p<0.05$.

\section{Results}

\section{Patient demographic and operative data}

Sixty-nine patients were enrolled in this study, with an average age of $63.1 \pm 11.0$ years, and $56.5 \%(36 / 69)$ were female. Thirty-two consecutive patients $(n=32)$ underwent LLIF from May 2014 to February 2016 and were implanted with static interbody spacers. The patients were $68.8 \%$
Table 1. Baseline characteristics

\begin{tabular}{lcc} 
Characteristic & Expandable & Static \\
No. of patients & 37 & 32 \\
Sex & & \\
\hline \multicolumn{1}{c}{ Female } & $14(37.8)$ & $22(68.8)$ \\
\multicolumn{1}{c}{ Male } & $23(62.2)$ & $10(31.2)$ \\
\hline Age (yr) & $60.3 \pm 12.0(34-82)$ & $66.3 \pm 8.9(45-81)$ \\
\hline
\end{tabular}

Values are presented as number, number $(\%)$, or mean \pm standard deviation (range).

Table 2. Minimally invasive lateral lumbar interbody fusion procedure characteristics

\begin{tabular}{lcc}
\hline Characteristic & Expandable & \multicolumn{1}{c}{ Static } \\
\hline Type of surgery & & \\
\hline One-level & $13(22.8)$ & $9(28.1)$ \\
\hline Two-level & & \\
\hline Levels instrumented & $1(2.2)$ & 0 \\
\hline L1-L2 & $10(21.7)$ & $7(17.1)$ \\
\hline L2-L3 & $17(37.0)$ & $15(36.6)$ \\
\hline L3-L4 & $18(39.1)$ & $19(46.3)$ \\
\hline L4-L5 & & \\
\hline Mean estimated blood loss (mL) & $21.7 \pm 12.3$ & $38.9 \pm 30.1$ \\
\hline One-level & $23.9 \pm 6.5$ & $86.7 \pm 155.9$ \\
\hline Two-level & & \\
\hline Mean operative time (min) & $57.8 \pm 15.3$ & $65.0 \pm 39.6$ \\
\hline One-level & $93.6 \pm 14.0$ & $84.1 \pm 32.2$ \\
\hline Two-level & & \\
\hline Mean length of hospital stay (day) & $3.8 \pm 1.6$ & $2.1 \pm 1.2$ \\
\hline One-level & $4.2 \pm 2.2$ & $2.6 \pm 1.9$ \\
\hline Two-level & & \\
\hline
\end{tabular}

Values are presented as number, number (\%), or mean \pm standard deviation (range).

$(22 / 32)$ female and $31.2 \%$ male $(10 / 32)$ with an average age of $66.3 \pm 8.9$ years (range, $45-81$ years). Thirty-seven consecutive patients $(\mathrm{n}=37$ ) underwent MIS-LLIF from August 2016 to November 2017 and were implanted with expandable interbody spacers. The patients were $37.8 \%$ $(14 / 37)$ female and $62.2 \%(23 / 37)$ male with an average age of $60.3 \pm 12.0$ years (range, $34-82$ years) (Table 1 ).

There were 87 spinal fusion levels, with $42.5 \%$ (37/87) at L4-L5 and $36.8 \%(32 / 87)$ at L3-L4. Of the 69 patients, $73.9 \%(51 / 59)$ were single level $(1 \mathrm{~L})$ procedures and $26.1 \%(18 / 69)$ were two-level fusion (2L). Mean operative time was similar between groups with the expandable 
Table 3. Mean difference of clinical outcomes and radiographic parameters

\begin{tabular}{|c|c|c|c|c|c|}
\hline Parameter & Device & 6 wk & $3 \mathrm{mo}$ & $6 \mathrm{mo}$ & $12 \mathrm{mo}$ \\
\hline \multirow[t]{2}{*}{ Visual Analog Scale back and leg pain } & Expandable & $3.9 \pm 1.2^{*}$ & $5.4 \pm 1.1$ & $5.8 \pm 1.4^{*}$ & $6.7 \pm 2.6^{*}$ \\
\hline & Static & $4.7 \pm 2.3$ & $5.1 \pm 2.3$ & $4.3 \pm 2.9$ & $5.1 \pm 2.6$ \\
\hline \multirow[t]{2}{*}{ Oswestry Disability Index } & Expandable & $33.4 \pm 12.4$ & $46.3 \pm 10.8^{*}$ & $54.6 \pm 12.7^{*}$ & $63.2 \pm 13.2^{*}$ \\
\hline & Static & $24.3 \pm 24.4$ & $28.8 \pm 20.6$ & $26.8 \pm 22.6$ & $29.8 \pm 23.4$ \\
\hline \multirow[t]{2}{*}{ Middle disk height (mm) } & Expandable & $5.8 \pm 5.0$ & $4.8 \pm 5.0$ & $4.4 \pm 3.8$ & $4.2 \pm 3.8$ \\
\hline & Static & $4.6 \pm 2.8$ & $4.1 \pm 3.1$ & $4.2 \pm 3.0$ & $3.9 \pm 3.2$ \\
\hline \multirow[t]{2}{*}{ Neuroforaminal height (mm) } & Expandable & $5.4 \pm 3.8^{*}$ & $3.9 \pm 3.7$ & $3.8 \pm 3.4^{*}$ & $3.4 \pm 3.7$ \\
\hline & Static & $2.5 \pm 3.5$ & $2.3 \pm 3.9$ & $1.8 \pm 3.3$ & $2.2 \pm 4.3$ \\
\hline \multirow[t]{2}{*}{ Segmental lordosis $\left({ }^{\circ}\right)$} & Expandable & $4.9 \pm 3.1^{*}$ & $4.5 \pm 3.0^{*}$ & $4.3 \pm 2.9^{*}$ & $3.7 \pm 2.9^{*}$ \\
\hline & Static & $0.6 \pm 5.1$ & $0.3 \pm 5.1$ & $0.2 \pm 5.6$ & $-0.3 \pm 4.6$ \\
\hline
\end{tabular}

Values are presented as mean \pm standard deviation. Change compared to preoperative value. ${ }^{*} p<0.05$ compared to static.

group averaging $57.8 \pm 15.3$ minutes for $1 \mathrm{~L}$ fusions and $93.6 \pm 14.0$ minutes for $2 \mathrm{~L}$ fusions, and the static group averaging $65.0 \pm 39.6$ minutes for $1 \mathrm{~L}$ and $84.1 \pm 32.2$ minutes for $2 \mathrm{~L}$. Length of hospital stay for the expandable group was $3.8 \pm 1.6$ days for $1 \mathrm{~L}$ fusions and $4.2 \pm 2.2$ days for $2 \mathrm{~L}$ fusions and the static group averaging 2.1 \pm 1.2 days for $1 \mathrm{~L}$ and 2.6 \pm 1.9 for $2 \mathrm{~L}$. Mean estimated blood loss for the expandable spacers was $21.7 \pm 12.3 \mathrm{~mL}$ for $1 \mathrm{~L}$ and $23.9 \pm 6.5$ $\mathrm{mL}$ for $2 \mathrm{~L}$ fusions and mean estimated blood loss for static interbody spacers was $38.9 \pm 30.1 \mathrm{~mL}$ for $1 \mathrm{~L}$ and $86.7 \pm 155.9 \mathrm{~mL}$ for $2 \mathrm{~L}$ fusions (Table 2 ).

\section{Clinical outcomes}

Patients reported improvements in both pain and level of disability and comparisons were made between the static and expandable groups by measuring their differences from mean baseline to 12-month follow-up. Mean preoperative VAS scores for back and/or leg pain decreased significantly in both groups $(p<0.001)$. The expandable group had a significantly greater decrease in pain of $6.7 \pm 1.3$ points at 12 months, whereas the mean change in the static group was $5.1 \pm 2.6$ points $(p=0.001)$. The expandable group also had a statistically greater decreases in VAS score at 6 months with their mean change being $5.8 \pm 1.4$ and the static group's mean VAS score change was $4.3 \pm 2.9$ ( $p=0.007)$. The mean differences between groups were not significant at 3 months, with the expandable group's VAS score decreasing by $5.4 \pm 1.1$ and the static group by $5.1 \pm 2.3$ ( $p=0.469)$. However, at 6-week follow-up, the static group had a significantly greater change in VAS scores with a difference of $4.7 \pm 2.3$ and $3.9 \pm 1.2(p=0.039)$ for the expandable group.

Both groups showed significant ODI improvement at 12 months $(p<0.001)$; however, the expandable group had a significantly greater decrease of $63.2 \pm 13.2$ points, compared to the static group which had a mean difference of $29.8 \pm 23.4$ points, at 12 months postoperatively $(p<0.001)$. Additionally, postoperative mean ODI scores were shown to be significantly better in the expandable group at 3 (expandable, $46.3 \pm 10.8$; static, 28.8 $\pm 20.3 ; p<0.001$ )

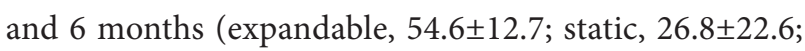
$p<0.001)$. At 6 weeks, the expandable group showed a greater mean ODI difference than the static group approaching significance (expandable, 33.4 \pm 12.4 ; static, 24.3 $\pm 24.4 ; p=0.052$ ) (Table 3).

\section{Radiographic outcomes}

Preoperative segmental lordosis improved significantly by a mean of $3.7^{\circ} \pm 2.9^{\circ}$ at 12 months postoperative for the expandable group $(p<0.001)$. Conversely, the static group had a slight decrease at 12 months from baseline $\left(-0.27^{\circ} \pm 4.6^{\circ}, p=0.712\right)$. Mean differences for postoperative segmental lordosis were significantly greater in the expandable group across all time intervals compared to the static group $(p<0.001)$ (Table 3$)$. The preoperative $\mathrm{DH}$ increased significantly at 12 months postoperative for both static and expandable groups, with a mean improvement of $4.2 \pm 3.8 \mathrm{~mm}$ for the expandable group and $3.9 \pm 3.2 \mathrm{~mm}$ for the static group $(p<0.001)$. Postoperative improvements in $\mathrm{DH}$ showed no differences of significance be- 
tween groups across all time intervals. Mean preoperative $\mathrm{NH}$ increased by $3.4 \pm 3.7 \mathrm{~mm}$ for the expandable group $(p<0.001)$ and by $2.2 \pm 4.3 \mathrm{~mm}$ for the static group at 12 months postoperative ( $p=0.002$ ); however, the differences between the groups were not significant $(p=0.162)$. Mean $\mathrm{NH}$ change was statistically greater in the expandable group at 6 weeks (expandable, $5.4 \pm 3.8 \mathrm{~mm}$; static, $2.5 \pm 3.5$ $\mathrm{mm})(p<0.001)$, and 6 months postoperatively (expandable, $3.8 \pm 3.4 \mathrm{~mm}$; static, $1.8 \pm 3.3 \mathrm{~mm})(p=0.008)$. However, there were no significant differences noted between groups for $\mathrm{NH}$ at 3 or 12 months (Table 3 ).

\section{Implant-related observations}

Implant subsidence was significantly higher in the static group (32.4\%, 12/37 levels) compared to the expandable group $(2.2 \%, 1 / 46$ levels $)(p<0.05)$. Subsidence rates were shown to be statistically significant using the Mann-Whitney $U$-test. All cases of subsidence were asymptomatic with no revision surgery necessary.

\section{Discussion}

In this study, the change in segmental lordosis, VAS, and ODI were significantly higher at 12-month follow-up with the use of expandable interbody spacers compared to static interbody spacers. Both groups demonstrated significant improvements in DH and NH. Historically, static lumbar interbody spacers were used to restore $\mathrm{DH}$ and achieve sagittal correction. Larger implants are placed to allow for indirect decompression and optimal sagittal correction [24]. Nonetheless, static interbody spacers have been associated with higher rates of subsidence, which leads to loss of $\mathrm{DH}$ and lordosis potentially compromising stability [26,27]. Currently, the literature is sparse on comparative studies between expandable and static interbody spacers with LLIF, thereby making correlations between the two groups challenging.

Good clinical outcomes in LLIF are contingent on restoring sagittal alignment by improving essential factors such as correction of $\mathrm{DH}$ and segmental lordosis [7]. The focus of this study was to compared the mean change in radiographic and patient reported outcome parameters at specific time intervals. We found that VAS, ODI, and segmental lordosis outcomes were better at 12-month follow-up with the use of expandable interbody spacers than the use of static interbody spacers. Marchi et al.
[28] demonstrated a $61 \%$ increase from baseline in $\mathrm{DH}$ at 12-month follow-up with stand-alone LLIF with static polyetheretherketone cages. However, their subsidence rate (grade I and II) was relatively high at $17.3 \%$ [28]. The current study showed a $43 \%$ increase in $\mathrm{DH}$ at 12 -month follow-up (preoperative mean DH, 8.8 $2.8 \mathrm{~mm}$; 12 -month mean $\mathrm{DH}, 12.6 \pm 2.9 \mathrm{~mm}$ ) for the static group and a $62 \%$ increase (preoperative mean $\mathrm{DH}, 6.9 \pm 3.5 \mathrm{~mm}$; 12 -month mean $\mathrm{DH}, 11.2 \pm 2.3 \mathrm{~mm}$ ) for the expandable group from baseline. Tohmeh et al. [29] studied 140 patients who underwent XLIF (T11-L5) with pedicle screws or lateral platting and found a $12.1 \%$ decrease in $\mathrm{DH}$ at 12 months using static cages. In the current study, the static interbody spacers showed a $6.0 \%$ decrease in mean $\mathrm{DH}$ and the expandable interbody spacers had a $1.9 \%$ decrease in $\mathrm{DH}$ from 6 weeks to 12 months postoperative. A significant increase in segmental lordosis angle of $69.8 \%$ at 12 months was found for the expandable group, whereas the static group showed a $2.0 \%$ decrease, which may be a factor for the better VAS and ODI outcomes observed in the expandable group. Endplate integrity is believed to be preserved with expandable interbody spacers due to less trialing, theoretically leading to an increase in segmental lordosis. Posterior fixation provides the stability necessary to maintain lordosis longevity. In this study, expandable interbody spacers had a significantly greater increase in segmental lordosis compared to static spacers. Numerous studies have shown that preserving and restoring sagittal alignment is a critical predictor in determining excellent short and long-term patient outcomes [7,26,27,30,31]. There was one patient (2.2\%) who experience subsidence in the expandable group compared to 12 cases $(32.4 \%)$ in the static group. In a systematic review by Macki et al. [32], the reported incidence of subsidence with LLIF was $10.3 \%$ ( $n=141$ out of 1,362 patients in 14 articles).

A few limitations existed for this study. The cohorts that were compared were from two spine surgeons with different specialties and different institutions. Author Y.L. is a neurosurgeon, while author R.F. is an orthopedic surgeon, both practicing in different institutions; however, both surgeons use similar surgical techniques. The radiographic measurements were conducted by different observers which creates another limitation. Preoperative radiographic measurements also differed between the two groups; however, comparing the mean differences helped mitigate this heterogeneity. Small sample size for each spacer subgroup (37 expandable, 32 static) as well as a 
short follow-up of 12 months also contributed to the study limitations. Lastly, patient selection between surgeons may be vastly different and may contribute to the outcome scores reported herein. A minimum 2-year follow-up is required to assess pseudoarthrosis. A long-term follow-up study is forthcoming to address these issues.

\section{Conclusions}

This study compared the mean change in radiographic and patient reported outcome parameters at specific time intervals and found that patient outcomes were better at 12 months postoperatively with the use of expandable interbody spacers than by using the static interbody spacers. Significant indirect decompression was achieved and maintained with LLIF up to 1-year follow-up from baseline in both expandable and static interbody spacer groups based on the observed increases in $\mathrm{DH}$ and $\mathrm{NH}$. Using expandable interbody spacers resulted in satisfactory outcomes and resulted in the expandable group having a significantly lower subsidence rate, greater segmental lordosis improvement, and better VAS and ODI outcomes compared to the static group at final follow-up. This study demonstrated the efficiency and durability of expandable interbody spacers when used in LLIF

\section{Conflict of Interest}

No potential conflict of interest relevant to this article was reported. Funding for this project was provided by the Musculoskeletal Education and Research Center (MERC), a Division of Globus Medical, Inc. Y.M.L. and R.F. are consultants for Globus Medical, Inc., and receive royalties on RISE-L (Globus Medical). Z.H., J.T., and Y.I.L. have no relationships to disclose. A.E. and C.L. are salaried employees of Globus Medical, Inc.

\section{References}

1. Ozgur BM, Aryan HE, Pimenta L, Taylor WR. Extreme lateral interbody fusion (XLIF): a novel surgical technique for anterior lumbar interbody fusion. Spine J 2006;6:435-43.

2. Lehmen JA, Gerber EJ. MIS lateral spine surgery: a systematic literature review of complications, outcomes, and economics. Eur Spine J 2015;24 Suppl 3:287-313.
3. Kotwal S, Kawaguchi S, Lebl D, et al. Minimally invasive lateral lumbar interbody fusion: clinical and radiographic outcome at a minimum 2-year followup. J Spinal Disord Tech 2015;28:119-25.

4. Bagby GW. Arthrodesis by the distraction-compression method using a stainless steel implant. Orthopedics 1988;11:931-4.

5. Kuslich SD, Ulstrom CL, Griffith SL, Ahern JW, Dowdle JD. The Bagby and Kuslich method of lumbar interbody fusion: history, techniques, and 2-year follow-up results of a United States prospective, multicenter trial. Spine (Phila Pa 1976) 1998;23:1267-78.

6. Kuslich SD, Danielson G, Dowdle JD, et al. Four-year follow-up results of lumbar spine arthrodesis using the Bagby and Kuslich lumbar fusion cage. Spine (Phila Pa 1976) 2000;25:2656-62.

7. Sembrano JN, Horazdovsky RD, Sharma AK, Yson SC, Santos ER, Polly DW Jr. Do lordotic cages provide better segmental lordosis versus nonlordotic cages in lateral lumbar interbody fusion (LLIF)? Clin Spine Surg 2017;30:E338-43.

8. Sharma AK, Kepler CK, Girardi FP, Cammisa FP, Huang RC, Sama AA. Lateral lumbar interbody fusion: clinical and radiographic outcomes at 1 year: a preliminary report. J Spinal Disord Tech 2011;24:24250.

9. Rodgers WB, Lehmen JA, Gerber EJ, Rodgers JA. Grade 2 spondylolisthesis at L4-5 treated by XLIF: safety and midterm results in the "worst case scenario". ScientificWorldJournal 2012;2012:356712.

10. Glassman SD, Bridwell K, Dimar JR, Horton W, Berven S, Schwab F. The impact of positive sagittal balance in adult spinal deformity. Spine (Phila $\mathrm{Pa} 1976$ ) 2005;30:2024-9.

11. Glassman SD, Berven S, Bridwell K, Horton W, Dimar JR. Correlation of radiographic parameters and clinical symptoms in adult scoliosis. Spine (Phila $\mathrm{Pa}$ 1976) 2005;30:682-8.

12. Le TV, Vivas AC, Dakwar E, Baaj AA, Uribe JS. The effect of the retroperitoneal transpsoas minimally invasive lateral interbody fusion on segmental and regional lumbar lordosis. ScientificWorldJournal 2012;2012:516706.

13. Godde S, Fritsch E, Dienst M, Kohn D. Influence of cage geometry on sagittal alignment in instrumented posterior lumbar interbody fusion. Spine (Phila $\mathrm{Pa}$ 1976) 2003;28:1693-9. 
14. Folman Y, Shabat S, Gepstein R. B-twin expandable spinal spacer for posterior lumbar interbody stabilization: mechanical testing. J Surg Orthop Adv 2006;15:203-8.

15. Abumi K, Panjabi MM, Kramer KM, Duranceau J, Oxland T, Crisco JJ. Biomechanical evaluation of lumbar spinal stability after graded facetectomies. Spine (Phila Pa 1976) 1990;15:1142-7.

16. Aoki Y, Yamagata M, Nakajima F, et al. Examining risk factors for posterior migration of fusion cages following transforaminal lumbar interbody fusion: a possible limitation of unilateral pedicle screw fixation. J Neurosurg Spine 2010;13:381-7.

17. Chen WJ, Lai PL, Tai CL, Chen LH, Niu CC. The effect of sagittal alignment on adjacent joint mobility after lumbar instrumentation: a biomechanical study of lumbar vertebrae in a porcine model. Clin Biomech (Bristol, Avon) 2004;19:763-8.

18. Malham GM, Ellis NJ, Parker RM, et al. Maintenance of segmental lordosis and disk height in stand-alone and instrumented extreme lateral interbody fusion (XLIF). Clin Spine Surg 2017;30:E90-8.

19. Kim SJ, Lee YS, Kim YB, Park SW, Hung VT. Clinical and radiological outcomes of a new cage for direct lateral lumbar interbody fusion. Korean J Spine 2014;11:145-51.

20. Elias WJ, Simmons NE, Kaptain GJ, Chadduck JB, Whitehill R. Complications of posterior lumbar interbody fusion when using a titanium threaded cage device. J Neurosurg 2000;93(1 Suppl):45-52.

21. Kim CW, Doerr TM, Luna IY, et al. Minimally invasive transforaminal lumbar interbody fusion using expandable technology: a clinical and radiographic analysis of 50 patients. World Neurosurg 2016;90:228-35.

22. Alimi M, Shin B, Macielak M, et al. Expandable polyaryl-ether-ether-ketone spacers for interbody distraction in the lumbar spine. Global Spine J 2015;5:169-78.

23. Salzmann SN, Shue J, Hughes AP. Lateral lumbar interbody fusion-outcomes and complications. Curr Rev Musculoskelet Med 2017;10:539-46.

24. Torretti J, Harris JA, Bucklen BS, Moldavsky M, Khalil SED. In vitro biomechanical and fluoroscopic study of a continuously expandable interbody spacer concerning its role in insertion force and segmental kinematics. Asian Spine J 2018;12:601-10.

25. Choi JY, Sung KH. Subsidence after anterior lumbar interbody fusion using paired stand-alone rectangular cages. Eur Spine J 2006;15:16-22.

26. Lazennec JY, Ramare S, Arafati N, et al. Sagittal alignment in lumbosacral fusion: relations between radiological parameters and pain. Eur Spine J 2000;9:4755.

27. Liang Y, Shi W, Jiang C, et al. Clinical outcomes and sagittal alignment of single-level unilateral instrumented transforaminal lumbar interbody fusion with a 4 to 5-year follow-up. Eur Spine J 2015;24:2560-6.

28. Marchi L, Abdala N, Oliveira L, Amaral R, Coutinho E, Pimenta L. Radiographic and clinical evaluation of cage subsidence after stand-alone lateral interbody fusion. J Neurosurg Spine 2013;19:110-8.

29. Tohmeh AG, Khorsand D, Watson B, Zielinski X. Radiographical and clinical evaluation of extreme lateral interbody fusion: effects of cage size and instrumentation type with a minimum of 1-year follow-up. Spine (Phila Pa 1976) 2014;39:E1582-91.

30. Mobbs RJ, Phan K, Malham G, Seex K, Rao PJ. Lumbar interbody fusion: techniques, indications and comparison of interbody fusion options including PLIF, TLIF, MI-TLIF, OLIF/ATP, LLIF and ALIF. J Spine Surg 2015;1:2-18.

31. Pimenta L, Tohmeh A, Jones D, et al. Rational decision making in a wide scenario of different minimally invasive lumbar interbody fusion approaches and devices. J Spine Surg 2018;4:142-55.

32. Macki M, Anand SK, Surapaneni A, Park P, Chang V. Subsidence rates after lateral lumbar interbody fusion: a systematic review. World Neurosurg 2019;122:599-606. 